events. I was allowed to write up the story of the Lithuanian girl's appeal to Khrushchev at the luncheon, and the editors printed it on the front page with my name in the by line. Another story, without a by line, appeared on an inside page, detailing the family's visit to the campus, but omitting the conversation with Mrs Khrushchev. The experience stimulated me to consider a career in journalism, but other events intervened in the fulfilment of the goal. Yet the Khrushchev visit was undoubtedly the highlight of my short journalistic career.

\section{Resignation and death}

Khrushchev was forced by his fellow politburo members to resign his p'sts in October 1964, and he died on 11 September 1971 at.the age of 77 . His obituary in Moscow simply referred to "personal pens: oner" Nikita Khrushchev, marking the obscurity he had been giver. since his forced retirement in 1964 . He was buried in the secont 1 ranking burial site in Moscow, the Novodevichy cemetery next I a former convent. A soviet artist, Ernst Neizvestny, who had $:-$ en berated publicly by Khrushchev for his work, offered to creat: a bust for his grave, and the family commissioned him to do so. ' $[$ ': e sculpted head was placed on his grave in September 1974.

By another coincidence, I was in Moscow in April 1975, acccn panying the then attorney general (chief legal representative and adviser) of California, Evelle J Younger, and his wife on a visit to the Soviet Union. I told Attorney General and Mrs Younger of my meeting with the Khrushchevs and asked their indulgence if I took a few minutes to pay my respects at his grave. They willingly, agreed. I explained that Khrushchev was still a "non-person" in his country, even in death, and that for that reason and the fact that his grave site was undoubtedly not an approved tourist site our assigned Intourist guide might not want to take us. Because Intourist was treating us as VIP guests (in apparent response to the Soviet government's interest in the state of California) I had developed a strategy to cope with the expected refusal, and thus I asked them to bear with me when I insisted.
On Sunday morning our Intourist driver and guide picked us up at our hotel. The guide was a young, unfriendly woman who had already planned an itinerary for us. When we were in the car and on our way I winked at the Youngers and announced to the guide that we wanted to go to the Novodevichy cemetery to visit the grave of former Premier Khrushchev.

Her face turned ashen, and she began a rapid fire conversation in Russian with the driver. Then she said: "It's impossible, out of the question!" Having planned my response carefully, I looked straight at the guide and spoke slowly and firmly: "If we are not taken immediately to the Novodevichy cemetery and shown the grave of Premier Khrushchev you are to immediately return us to our hotel and explain later to your superiors why we stopped touring this morning."

This led to at least three minutes of anxious conversation between driver and guide, and an announcement that we would be taken to the cemetery. As I had hoped, the alternative of our not touring had even worse potential consequences for our guide in the eyes of her superiors, but she made her point once we arrived. Taking us to the middle of the cemetery, she pointed to a far corner where a gold coloured bust was visible, and said simply: "There!" Then, quickly leaving us, she walked back to the car. We spent a few minutes at the grave site, and I silently recalled the 1959 conversations.

In August $1984 \mathrm{Mrs}$ Khrushchev died at the age of 84 . She also was referred to in the Moscow newspapers as a "personal pensioner" under her maiden name of Kukharchuk and, it is reported, she was buried beside her husband.

The photographs of $\mathrm{Mr}$ and Mrs Khrushchev are reproduced by courtesy of the University of Pittsburgh archives; that of Mr Khrushchev's tomb was supplied by Topham Picture Library.

Division of Pulmonary and Critical Care Medicine, Department of Medicine, UCLA School of Medicine, Los Angeles, CA 90024-1690, USA

LESLIE STEVEN ROTHENBERG, JD, adjunct associate professor of medicine

\title{
A stay in a central Soviet hospital
}

\author{
L W LAUSTE
}

I was visiting Mongolia with a colleague when I contracted an acute respiratory infection which led to my admission to hospital in Irkutsk in Soviet Central Asia. This is the first year that Mongolia has allowed individual tourists, and the object of our tour was to see a little of the country and the people. We visited Inner Mongolia and the Grasslands and continued by train to Ulan Bator, the capital of Mongolia. Outer Mongolia was under Russian rule from 1924 and became independent in 1945 under the Yalta Sino-Russian agreement; but it still has a large Russian presence, which the people resent but cannot oppose. They are intensely nationalistic, with their own language, currency, postage, time, and now developing industry, although most of the people are still nomads, living in yurts. The main attraction in Outer Mongolia is Karakorum-the military capital established by Genghis Khan in 1220 and now but a heap of stones.

When we returned to Ulan Bator from visiting Karakorum there was bright sunshine but a cold wind, and that evening I became ill with a severe respiratory infection, probably spreading from a mild tracheitis I had had for two or three days. Clearly I could not continue the tour to Irkutsk by train as planned but I thought I could make the journey to London by air. We got seats on the plane to Irkutsk-a short and easy journey, but it proved too much for me. Once at a hotel in Irkutsk I agreed that the doctor should be called. Two young doctors came and said-as I knew they wouldthat I should go to hospital. I was admitted with what proved to be lobar pneumonia and stayed there three weeks.

\section{Care and comfort}

My medical care was excellent. The day after admission my chest was radiographed, an electrocardiogram was done, and blood was taken for various tests. Curiously no sputum was sent for culture or urine examined until two days later. I cannot speak of the standard of $x$ ray equipment or films, but the apparatus certainly worked without trouble, and the electocardiograph had as many leads as Dr Douglas Chamberlain has on his machines. Repeat blood examinations were done twice and a repeat radiograph and electrocardiogram were performed two weeks later.

I was under the care of a physician-a pleasant woman of 
seniority, who prescribed treatment and visited at least three times a day, at about 815 am to inquire how I was, at about 10 am for complete examination, and later in the afternoon before leaving the hospital, and occasionally at other times for various reasons. This happened every day except Sunday, when a young doctor usually looked in. I was very ill for the first week and the professor came in twice for consultation, one problem being that I am sensitive to some antibiotics. Treatment was at first by medicine and tablets by mouth and injections, which were soon supplemented by intravenous drips of antibiotics and other intravenous injections, and later with intramuscular injections. Because I was unable to take food the medicines by mouth produced vomiting and had to be stopped.

The room was small with two beds; it was warm with good central heating, and a large window was kept a little open for good fresh air. The beds were iron with springs and a mattress and quite comfortable; a refrigerator, two armchairs, two small lockers, and one small chair completed the furniture. A very small room with a toilet, washbasin, and a door was next to the entrance. Although not luxurious, this was adequate and everything worked, and the lack of a wooden seat did not matter. There were good bed lights, a general light, a bell, and piped oxygen.

When I arrived the other bed was occupied by a young English tour leader with acute gastritis, who vomited and groaned half the night, then fell asleep, and was better when he woke up-when he discharged himself. Then a Russian was admitted, an academic I think, with back trouble, but he was ambulant and he was discharged after a few days. He was very good to me, as at first I was too weak to take the few steps to the toilet and he helped me. I had the room to myself for the rest of the time, although once a pleasant elderly man connected with the theatre was admitted for a few hours. I was pleased to be on my own as I did not like the lights being put on.

I found the food unsuitable, especially for an ill person and wrongly concentrated into a few hours. Breakfast was usually about $9 \mathrm{am}$, lunch about $1 \mathrm{pm}$, and supper at $530 \mathrm{pm}$. Russians are not great cooks. Meals tended to be heavy and fatty, even kasha being served with melted butter. Also there was sour milk or cream-kefir and smetana - with nearly every meal. I did manage to get hot milk sometimes and occasionally in the evening, but there seemed to be little liaison between the medical staff and the kitchen. I eventually said I was a vegetarian. Vegetable soups were reasonable and there was plenty of mashed potato; the fruit was good when available, especially the plums. Twice the cook came to see me, clearly concerned that I sent most food back untouched, and once suggested an omelette. It was thick and stone cold, but I ate it to show good will.

\section{Five tiers of attention}

There was no nursing as we know it and attention was arranged in five tiers.

The domestic was responsible for cleaning the room, emptying the large jar acting as sputum pot, and changing the bed linen once a week. This was clean and well laundered and I was provided with yellow striped pyjamas which fitted. The domestic was a middle aged morose woman, who seemed unenthusiastic about her work. Cleaning was essentially.mopping the floor and surfaces such as the refrigerator and locker. This was done daily but the armchairs or beds were never moved, which made it impossible to clean thoroughly. When I arrived my bed light, which shared a common switch with the refrigerator, did not work. She was delighted when I told her: she set to work, made the light work, and put on a two way switch. I think she was an electrician at heart.

The general nurse brought the medicines and food trays and took me to the $x$ ray department. She made no attempt at any nursing procedure such as making the bed or washing. My bed therefore remained unmade except when it was changed once a week until I was strong enough to do it myself. At first I was not strong enough to stand at the washbasin, so I remained unwashed for some 10 days except for rinsing my hands.
The injection nurses who gave the intramuscular injections were efficient and nearly always on time. I think they confined their work to this. They were, for example, different from the intravenous nurse, who seemed to do all the intravenous therapy for the whole floor. She was elderly with grey hair peeping from under her cap, and she was an expert. Every needle went in first time, the position was comfortable, and the drip was set at an exact rate so that she returned exactly on time to change the bottle. Only once did I have to ring because the bottle needed changing, and another nurse did this.

The night staff seemed to change more frequently and were often men. They took temperatures usually between 7 and 730 am and 7 and $730 \mathrm{pm}$ and gave medicines and on occasion oxygen and gargles.

As everywhere, the nurses varied, but most were kind and I would say dedicated, though I suspect that the authorities have staffing problems at times.

What I felt most was lacking was a matron in overall charge. My impression was that the staff were in separate compartments. Also the meals were concentrated into a few hours and then there was a long gap of 15 hours. The nights were long and, unless I was having injections, I saw no one for 12 hours.

\section{Recovery}

By the second week I was starting to improve, though the injections continued for another week and later I had a new treatment with what I took to be short wave diathermy and massage of the chest wall. Two weeks after admission I felt much better and asked if I could return to England the following weekend. At first my doctor said no because the chest radiograph was not clear but later, after discussion, agreed and arrangements were made. I was to have a doctor to accompany me to Moscow, where I would stay the night, and to take me to the airport and put me on the plane for the much shorter journey to London, where I would be met by my family. All this was arranged by my doctor, Intourist, and the British Embassy. I really should have stayed a week longer, but I was anxious to get home for more suitable food and I had come to dread the long nights.

During the last three or four days I took short walks on the floor to strengthen my legs and noted that there were 16 rooms of different sizes but most with 10 beds, so there must have been 100 or more patients, all medical. Most patients were ambulant but some were curled up in bed or on drips. Beds were the same as mine, with short headrests and very close together. Most patients must have gone to a dining room for meals. All the rooms were full and once beds were made on benches for two patients in the corridor. I could not decide what was wrong with any of the patients, except that some elderly women looked myxoedematous.

In one respect I was more fortunate than a recent correspondent who recounted the story of her stay in a Soviet hospital ${ }^{1}$ in that I have some knowledge of Russian and had few language problems in hospital. During the war I had occasion to look after many Russians and learnt to take a medical history in their language and I have since studied Russian but, alas, forgotten most. The Intourist interpreter came frequently and always if there was anything important to discuss.

Without treatment I do not think I would have recovered, and I am forever grateful to the medical, nursing, and ancillary staff of the hospital.

\section{Reference}

1 Trott DJ. Soviet health care at first hand. Br Med f 1987;295:1282-3.

Brighton BN2 5RE

L W LAUSTE, FRCS, retired surgeon 